\title{
Phase Contrast Microscopy
}

\author{
Maksymilian Pluta, FELLOW SPIE \\ Institute of Applied Optics \\ Kamionkowska 18 \\ 03-805 Warsaw, Poland
}

\begin{abstract}
This special section on phase contrast microscopy was preceded by an international conference on phase contrast $(\mathrm{PhC})$ and differential interference contrast (DIC) held in Warsaw, Poland, October 19-21, 1992, and is coincident with the 60th anniversary of Frits Zernike's invention of the PhC method, the 40th anniversary of Zernike's Nobel Prize in physics for $\mathrm{PhC}$ microscopy, and the 40th anniversary of Nomarski's DIC system. To be exact, however, only the second of these anniversaries is truly coincident with this special section, while the others occur about a year before or after.

The PhC/DIC conference included 11 invited lectures and about 30 regular papers on theories, developments, and applications of PhC/DIC methods and related techniques. Fifteen contributions dealt with $\mathrm{PhC}$ microscopy. Ten of these were selected for a critical review, but only six papers were accepted for publication in this special section. These six are supplemented by three other archival papers prepared by the guest editor himself. Such a guest-editorial practice is rather unconventional, but I have been strongly interested in $\mathrm{PhC}$ microscopy for nearly 40 years, and these anniversaries offer an extraordinary opportunity to present my own contributions. In self-justification I would only note that this special section is the first (and possibly also the last) occasion to present soot phase contrast microscopy in detail (and free from mysteries or secrets) in a distinguished international journal on applied or engineering optics.
\end{abstract}

The special section begins appropriately with a paper by $\mathrm{H}$. A. Ferwerda (Fig. 1) from Zernike's own University of Groningen. His invited paper on the life and achievements of Frits Zernike is not only interesting from a scientific point of view, but also reveals some unknown facts about Zernike's attitude and modesty toward his research and scientific achievements. I think that Ferwerda's paper (supplemented by my Addendum) deserves to be read by a large community of scientists and researchers.

The next paper deals with some imaging problems in the visualization of phase objects using $\mathrm{PhC}$ and related techniques. R. Jóźwicki (Fig. 2) applies his "distorter" theory to the visualization and then excellently passes to the vector interpretation of phase object imagery within the $\mathrm{PhC}$ and related techniques. I believe that his paper is a result of our perpetual dispute or even controversy concerning the vector theory of the phase contrast method. This theory was initiated by Zernike himself and then developed in detail by R. Barer, but was qualified by Jóźwicki as a scientific misconception. My replies were as follows: The vector theory of phase contrast is a

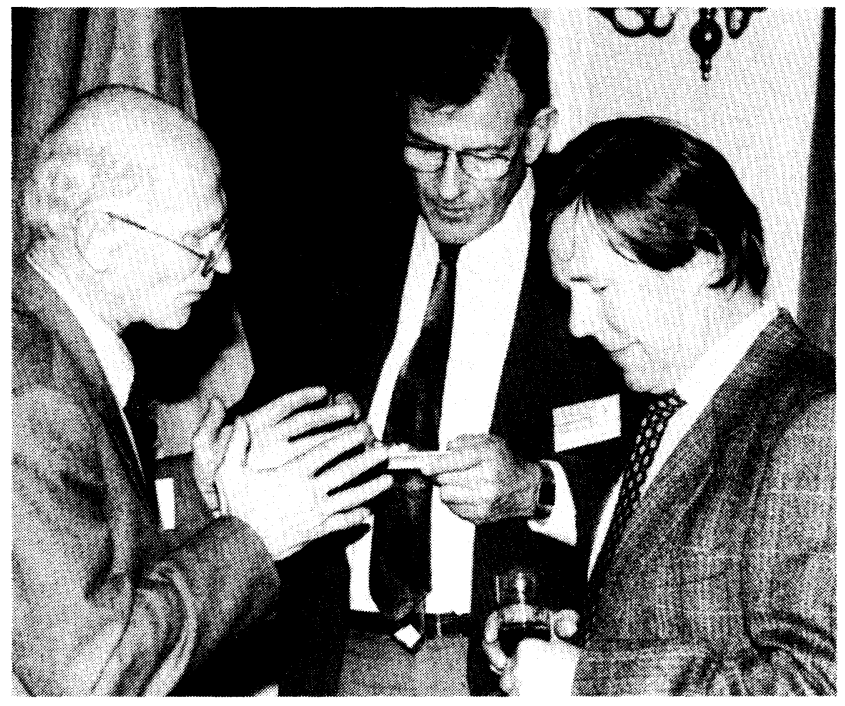

Fig. 1 Professor Hedzer A. Ferwerda (center) with Professors Vladimir P. Tychinsky (left) and Colin T. R. Sheppard at the gettogether cocktail party at the $\mathrm{PhC} / \mathrm{DIC}$ conference.

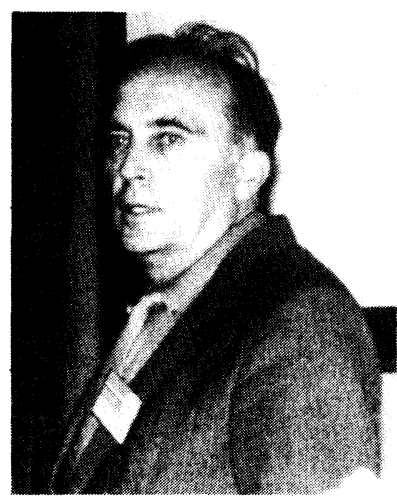

Fig. 2 Professor Romuald Jóźwicki as a session chairman.

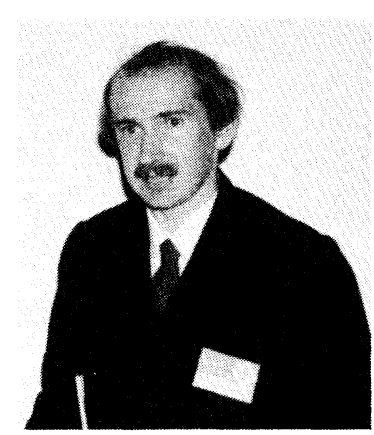

Fig. 3 Dariusz Litwin presenting his paper. very useful tool for all practitioners, especially biologists. I am glad that Jóźwicki has changed his opinion to agree with my point of view.

The next paper is by D. Litwin (Fig. 3) and deals with some specific properties of phase contrast imaging when a slit or line light source and strip-shaped phase plate are used. The properties have been examined by means of a highly advanced computer program that enables the Fourier transform 


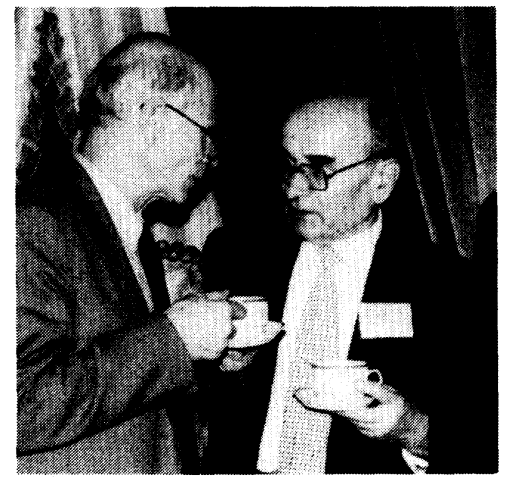

Fig. 4 The guest editor (center) with Professor Vladimir P. Tychinsky (left) at the get-together cocktail party.

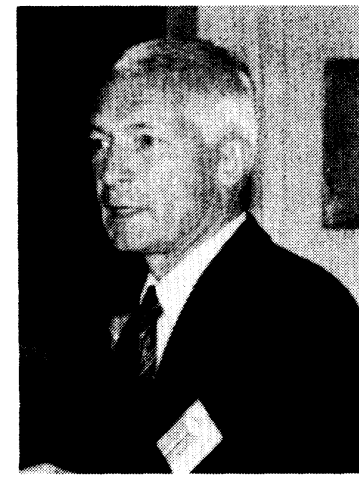

Fig. 5 Dr. Heinz Gundlach presenting his invited paper. approach and digital filtering process to be applied for the simulation of phase contrast imaging. However, neither the author nor the referee noticed that the same problem was examined by G. Nomarski ${ }^{1} 40$ years ago, but by means of an approach based on an analysis of the image contrast as a function of the azimuth in the object and objective back focal planes. The results obtained and conclusions drawn by Nomarski and Litwin are similar, except no mention is made in Nomarski's paper about the possible application of such a phase contrast arrangement to a quantitative characterization of optical fibers.

The fifth and sixth papers are the ones by the guest editor (Fig. 4) that have already been mentioned. I am still surprised at how many variable phase contrast devices of the polanret type were described in the past, and yet the simplest one was not perceived. However, this and other phase contrast devices are almost completely disqualified from biological applications in the next paper. Its author, H. Gundlach (Fig. 5.), prefers Nomarski's DIC system for exploring living cells and marine biology. He emphasizes, in particular, the ability of this system to section optically the cells and cell organelles. This is true, but Fig. 22 in my paper on highly sensitive phase contrast microscopy shows that the negative phase contrast device KFA also has the potential to produce effective optical sections of single cells.

The next paper is by M. Bożyk (Fig. 6). More than 10 years ago, she stated that the KFA device with soot phase rings can be useful for the determination of the most essential parameters of single-mode optical fibers. Now she discusses this problem in more detail, and the results of her experiments are more optimistic than the theoretical ones reported by Litwin.

Although best known to physicists and opticists for phase contrast microscopy, Zernike was familiar with many other areas of science and engineering including statistical physics, diffraction gratings, coherence of light, correlation, and optical aberrations. To honor his broad scientific horizons, a review article on the quantitative studies of random phase objects with the help of optical correlation techniques ends

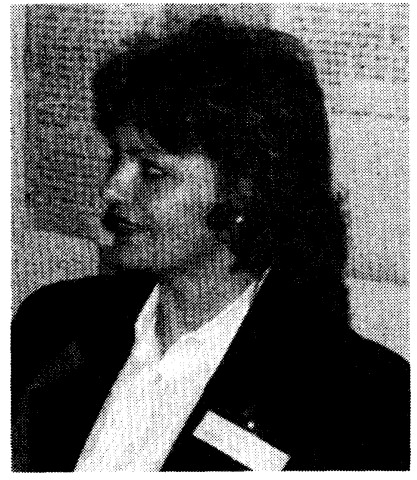

Fig. 6 Dr. Mirosława Bozyk at a conference poster session.

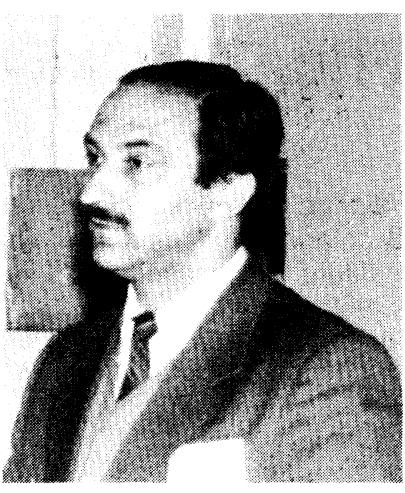

Fig. 7 Professor Oleg V. Angelsky answering questions after his invited lecture. this special section. Its authors, O. V. Angelsky (Fig. 7) and P.P. Maksimyak, are the experts in the field and discuss very competently the problems of correlation optics. Although no mention is made of phase contrast microscopy in their paper, this microscopic technique can be considered a stimulating one in the development of related areas including in particular the correlation diagnostics of phase objects and microstructures.

The photographs that accompany this editorial were taken by Barbara Mirkowska at the PhC/DIC conference.

I am grateful to all the authors and reviewers who were most cooperative with both the PhC/DIC conference and this special section. My sincere thanks to Brian J. Thompson and Lorretta Palagi and the rest of the Optical Engineering staff for their patience and help with the editorial and publishing processes.

\section{Reference}

1. G. Nomarski, "Lame de phase en forme de bande étroite, ses propriétés et ses applications," in Contraste de phase et contraste par interférences, M. Françon, Ed., pp. 185-196, Éditions de la revue d'Optique théorique et instrumentale, Paris (1952).

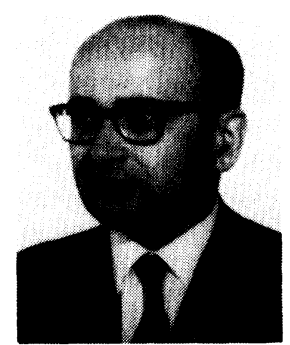

Maksymilian Pluta received his higher education in physics from the Jagiellonian University, Krakow, and Warsaw University (1949-1954). In 1954 he joined the Central Laboratory of Optics (now the Institute of Applied Optics), where he has been head and organizer of the Department of Physical Optics. He earned the $\mathrm{PhD}$ degree in applied optics and received, in 1982, the scientific title and position of professor. Formany years he has been associated with the Institute of Physics, Warsaw University of Technology, where he is active as a professor conferring doctoral degrees in applied optics. He is the author of several scientific books, more than 120 papers, and 26 patents. Since 1985 Pluta has been a member of SPIE and currently is chairman of the SPIE's Polish Chapter. 